Received: August 13, 2017

Revision received: May 12, 2018

\title{
Applied Research on Cognitive Linguistic Philosophy in Chinese Teaching
}

\author{
Tongyan Zhou $^{1}$ \\ Jinan University
}

\begin{abstract}
As the world's second largest economy, China occupies a pivotal position on the international stage, which makes Chinese a very commercial language today. Language is closely related to philosophy in cognitive science. Philosophical thoughts in different periods directly influence the development of language research. The experiential philosophy developed on the basis of the criticism of the traditional philosophical view, insisting that language is formed under the influence of human experience and cognition. The language is studied according to the principle of "reality-cognition-language", so the experience philosophy has also become the philosophical foundation of cognitive linguistics. Based on the theory of cognitive linguistic philosophy, this paper takes the Chinese teaching in middle schools in Myanmar as the research object, investigates the Chinese teaching situation in Myanmar middle schools, and analyzes the specific situation of Chinese language development in middle schools. Furthermore, it sums up the problems in the development of overseas Chinese teaching and gives some feasible suggestions. At the same time, it is also hoped that the problems in Chinese teaching management, Chinese teaching implementation, and classroom management will be improved, thus promoting the further professionalization and scientificization of overseas Chinese teaching.
\end{abstract}

\section{Keywords}

Cognitive Linguistic $・$ Experience Philosophy $\bullet$ Chinese Teaching $\bullet$ Applied Research

${ }^{1}$ Correspondence to: Tongyan Zhou, College of Chinese Language and Culture, Jinan University, Guangzhou 510610, China. Email: zhty8263@126.com

Citation: Zhou, T. Y. (2018). Applied Research on Cognitive Linguistic Philosophy in Chinese Teaching. Educational Sciences: Theory \& Practice, 18(5), 2373-2385. http://dx.doi.org/10.12738/estp.2018.5.136 
Language teaching is the process of mastering a certain language through the form of systematic teaching, and naturally focuses on "language. "The content of language is nothing more than speech, vocabulary and grammar. Therefore, language teaching focuses on phonetic teaching, vocabulary teaching, and sentence teaching. The teaching method is mainly the training of listening, speaking, reading and writing. The "language" of Chinese teaching refers to language, and the "literature" refers to literature. The content of literature includes literary common sense, ideological content, expression method, aesthetic taste and so on. Therefore, Chinese teaching focuses on appreciation, analysis, infection, and edification (Kubanyiova \& Feryok, 2015; Duan et al., 2015). The orientation of the language teaching mode involves a series of questions such as training objectives, textbook writing, and teaching methods. Therefore, this is a question of teaching philosophy. This teaching concept has not yet been able to have a position that is accepted by everyone.

With the rise of "Chinese fever" in various parts of the world, various forms of Chinese language tuition classes, Chinese tutoring classes, Chinese schools and Chinese schools in various regions of the world have continued to expand and expand. Chinese teaching has two modes of teaching overseas, one is the teaching mode of Chinese as a mother tongue, and the other is the teaching mode of Chinese as a second language. A school founded by a local Chinese is called a Chinese school. There are more Chinese-language teaching methods. The other is based on the mode of teaching Chinese as a second language. This has brought a certain degree of confusion and hindrance to overseas Chinese teaching. Overseas Chinese textbooks are not uniform and the course names are different (Koh, Burke, Luke, Gong \& Tan, 2018; Wu, 2018). The difference in name reflects the difference in teaching philosophy and also reflects the difference in teaching mode. So, which model is more in line with the objective reality of Chinese teaching in Southeast Asia, and thus produce better teaching results? Cognitive linguistics based on experiential philosophy holds that natural language is the product of human mind, and its organizational principles are no different from other cognitive organizational principles. As a field of human cognition, language is closely related to other cognitive fields, and it is also a reflection of the interaction of psychological, cultural, social and ecological factors (Tsai \& Wang 2015). The language structure depends on and reflects the formation process of the concept, and the formation process of the concept is based on our own experience. That is to say, language is not a system composed of arbitrary symbols. Its structure is related to human conceptual knowledge, physical experience and the function of discourse. Language has iconicity and is based on them. Therefore, experience philosophy has also become the philosophical foundation of cognitive linguistics.

Based on the theory of cognitive linguistic philosophy, this paper takes the middle school Chinese teaching in Myanmar as the research object, investigates the Chinese teaching situation in Myanmar middle schools, and analyzes the specific situation of Chinese language development in middle schools. Furthermore, it sums up the problems in the development of overseas Chinese teaching and gives some feasible suggestions. It is also hoped that problems in Chinese teaching management, Chinese teaching implementation, and classroom management will be improved, thus promoting the further professionalization and scientificization of overseas Chinese teaching. 


\section{The basis of the philosophical view of cognitive language}

The philosophical basis of cognitive linguistics is the experience of philosophy. Inquiring about literature and other materials, the summary of this study on the concept of experience philosophy is shown in Table 1 .

The experiential philosophy includes three basic principles: the experiential of the mind, the unconsciousness of the cognition, and the metaphor of the mind.

The experience of the mind. Categories, concepts, reasoning, and mind are formed through cognitive processing based on objective external perceptions and experiences (especially by sensory motor systems). There is an intermediate level of thinking or cognition between language and reality: language-cognition-reality.

Unconsciousness of understanding. We do things unconsciously and calmly, but once we get out of this cultural circle of self and into a heterogeneous environment, this unconscious becomes a deliberate and conscious act. We will consciously consider whether our actions are effective in this state of culture. But once you become familiar with this different culture and gradually adapt to it, conscious behavior will soon become unconscious again.

Metaphorical thinking. Metaphor is the normal way for human beings to understand the world. It is the characteristic of all human beings and is universally present in the culture and language of the world. Metaphors are characterized by experience, automatic unconsciousness, and abstraction (Zima, 2013)

Table 1

Summary of Views on the View of Experience Philosophy

\begin{tabular}{ll}
\hline $\begin{array}{l}\text { Subjectivity and } \\
\text { dependence }\end{array}$ & $\begin{array}{l}\text { Objective existence is not independent of human consciousness, but is } \\
\text { recognized through the subjective role of human beings. Human factors cannot } \\
\text { be ignored. }\end{array}$ \\
\hline $\begin{array}{l}\text { Experiential and } \\
\text { interactive }\end{array}$ & $\begin{array}{l}\text { The mind is not separated from the body. The human understanding of the } \\
\text { objective world is based on the human practical experience. This is the result of } \\
\text { interaction between the body and the objective outside world. }\end{array}$ \\
\hline $\begin{array}{l}\text { Metaphorical and } \\
\text { gestalt }\end{array}$ & $\begin{array}{l}\text { People are subjective and active. In the process of understanding the mind to the } \\
\text { outside world, they use metaphors and metaphors to broaden their thinking and } \\
\text { enhance their understanding of the objective outside world. }\end{array}$ \\
\hline $\begin{array}{l}\text { Conceptual structure is } \\
\text { non-symbolic and } \\
\text { constructive }\end{array}$ & $\begin{array}{l}\text { Describe the conceptual structure of humans with cognitive methods such as } \\
\text { cognitive models and literacy }\end{array}$ \\
$\begin{array}{l}\text { Ambiguity and } \\
\text { integration of the } \\
\text { meaning system }\end{array}$ & $\begin{array}{l}\text { The philosophy of experience believes that meaning is a mental phenomenon } \\
\text { based on experience. It is the result of interaction between subject and object. It } \\
\text { is dynamic, relativistic and ambiguous. It cannot be obtained by symbolic } \\
\text { operations by simple combination and formalism. }\end{array}$ \\
\hline
\end{tabular}

\section{Overview of Chinese Teaching}

Chinese teaching originated from the needs of the Chinese community (including the social needs of the country in which it is located). The various teachings initiated by the Chinese community in history have all originated from the fundamental interests of ethnic society and have the fundamental significance of inheriting ethnic language culture. Therefore, Chinese teaching covers both the teaching of ethnic languages and cultures of various forms and names established by the Chinese community, as well as the teaching of all levels of 
Zhou / Applied Research on Cognitive Linguistic Philosophy in Chinese Teaching.

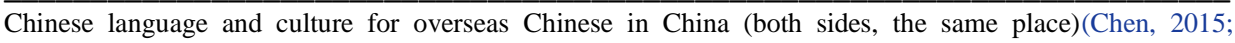
Kubanyiova, 2015). Think of Chinese teaching as a complete teaching system, in addition to recognizing that it has its own unique teaching philosophy, teaching objectives, curriculum, teaching materials, teaching evaluation, teacher training, managerial leadership system and Chinese community, The historical perspective pays attention to enough social time and space. In different historical periods, they all have common teaching objects and common teaching purposes, common teaching organization forms and common teaching contents, all shouldering the common historical mission and following the common development law; In the exploration of practice and theory, all work together and build a common discipline system. Judging from the information currently available, Chinese teaching in various places has the same teaching objectives; The status of Chinese teaching is widely recognized in the local area and has been incorporated into the teaching system of the host country to become a multicultural one; Chinese language teaching around the world has a clear management system and management institutions; Various types of teaching entities at all levels of school teaching and nonschool teaching; There are relatively stable textbooks written according to the teaching requirements (Sakita, 2006); There are common standards and means of teaching evaluation; there are stable students; and international cooperation.

\section{The Nature and Characteristics of Chinese Teaching from the Perspective of Cognitive Linguistic Philosophy}

The core problem of Chinese teaching is to inherit national language and culture in different social and environmental conditions. Whether it is the teaching stage of Chinese schools in the past 100 years or the teaching stage of non-Chinese schools more than 100 years ago, the teaching objectives are basically the same. Therefore, the theoretical construction of the Chinese teaching discipline should be carried out around the core issue of upholding the characteristics of national culture and cultivating the ethnic linguistic and cultural qualities of ethnic offspring (Orton, 2016). The theoretical system and methodology system of the Chinese teaching discipline is constructed to solve the core problem of the objective existence of Chinese teaching. According to the development direction of philosophy, when people understand the world, they generally follow the order from outside to inside, from things to people. First is empiricism, only theory, or firmly believe that the world is understood through perceptual experience, or firmly believe in "introspection theory", "natural theory", from perceptual knowledge, and pursuing pure reason. This is the extreme of objective philosophy. Only experiential philosophy can dialectically explain the way humans understand the world, and strive to find the cognitive way behind the language (Hulstijn et al., 2014). It pays attention to the role of human factors in the process of understanding the world. Based on this, Chinese teaching has the following characteristics and characteristics.

\section{The nature of Chinese teaching}

Under similar conditions, it will inevitably present a similar form, which is the unique regularity and external manifestation of the Chinese teaching system. The pattern of Chinese teaching that has been repeated repeatedly during the trough and climax in the past 100 years has striking similarities, showing the historical inevitability 
and strong vitality of this system (Burns, Freeman \& Edwards, 2015). Therefore, the nature of Chinese teaching is shown in Table 2 .

Table 2

The Nature of Chinese Teaching Under the Philosophy of Cognitive Linguistics

The practice of the interaction between the subject and the object produces an understanding. The philosophical view of cognitive

Practice decision in Chinese linguistics "the experience of the mind. The correct understanding teaching consists of empirical knowledge and theoretical knowledge, expressed in terms of concepts and conceptual systems; Understanding is the perception that human beings use to correctly use the senses.

The level of understanding in The subject of experience is the perception and experience that people get Chinese teaching: experience through activities and practices. It is the empirical knowledge that people induction and theoretical generalization. obtain through repeated iterations, choose the same or similar experiences, and then obtain them through induction. It means that most of the thinking activities in the brain cannot be directly

Cognitive unconsciousness in Chinese teaching known, indicating that it is only an illusion to reach through the philosophical speculation and the deepening of human thinking and understanding.

\section{Research objects and research methods}

The research object of this study is 20 Chinese teacher volunteers from Hanban. These teachers are still teaching at various schools in Myanmar and have been teaching for more than half a year, and are familiar with the school and teaching work. In addition, the study also has a local Chinese teacher in Myanmar who has studied in China for 4 years. He has been working in a middle school in Myanmar for 5 years. The research methods of this study are mainly shown in Table 3.

Table 3

Research Methods

Collect the literature related to this research, and collect news about the Chinese Literature teaching school in Myanmar on the Internet, pay attention to the latest developments research method of the Indonesian Chinese School in the newspaper, and collect information related to the Chinese school in Myanmar.

In this study, 19 Chinese language teacher volunteers who taught in Chinese schools were interviewed by WeChat chat. The interviewed teachers can talk about all aspects

Interview method of the teaching school in a state of natural relaxation, just like chatting with good and questionnaire survey friends. For local Chinese teachers, we use face-to-face interviews; The author sorted out the questionnaire based on the interview results and conducted an investigation by issuing questionnaires to 10 other teachers. According to the questionnaire responded by the respondents, some interviews were conducted in detail. In this study, the interview content was compiled into an electronic format, and the Analysis data was collated and the feedback information was quantified according to the needs of the paper.

\section{Investigation and analysis of Chinese teaching in middle schools in Myanmar}

\section{Analysis of the faculty status of Chinese schools in middle schools in Myanmar}

A total of 187 Chinese teachers were enrolled in the 15 middle schools in Myanmar. Among the 15 schools, there are 126 Chinese teachers from China; There are 61 local Chinese teachers in Myanmar. It can be seen that Chinese teachers from China account for more than half of the Chinese teachers in these schools (see Figure 1). 


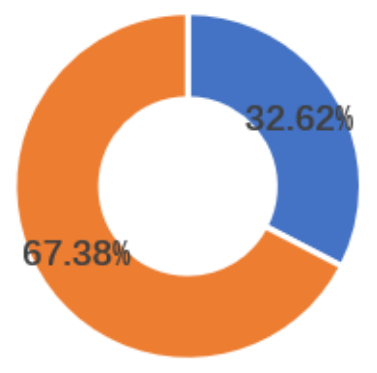

- Chinese teacher in Myanmar

\section{- Chinese teacher} from China

Figure 1. Composition of Chinese teachers in 15 middle schools in Myanmar.

These teachers from China are mainly Chinese teacher volunteers and Chinese public teachers, as well as some private Chinese teachers. In general, Chinese teachers from China are more mobile. Or because the Chinese teacher volunteers have a short term, or because of other reasons such as visas, they cannot continue to renew. This will affect the normal development and conduct of Chinese classes.

\section{Teaching methods}

According to the questionnaire, the teaching methods mainly used by these teachers in teaching include teaching methods, question and answer methods, reading methods, translation methods, and situational methods. Elementary school teachers also use fun teaching methods such as game law and competition law. The middle school teachers rarely touch the interesting teaching method, and more are the ordinary classroom teaching methods such as teaching method and question and answer method. According to the face-to-face interview of the teacher in this study, it is learned that the teacher knows little about the teaching method, and more because he has encountered problems in teaching, he wants to solve these methods. In addition to the textbooks, the teacher did not have any other teaching materials and did not take the initiative to access the materials. Many volunteer teachers interviewed said that the teaching of local teachers is mainly based on lectures, and does not pay attention to the communicative language. The teaching methods need to be improved.

\section{Teaching plan}

According to the questionnaire survey, about $36.77 \%$ percent of the secondary schools with Chinese language teaching plans. This part of the school has a special Chinese Department (or Chinese Department) to manage Chinese teaching, and also has systematic requirements for teaching progress and test assessment. Some of these schools require Chinese teachers of all grades to prepare a teaching plan and a monthly plan for each semester before the start of each semester. Some schools also require a weekly plan to be submitted each week. However, about $63.23 \%$ of Myanmar middle schools have no teaching plans. It is up to the teacher to decide what to teach and how to teach (see Figure 2). 


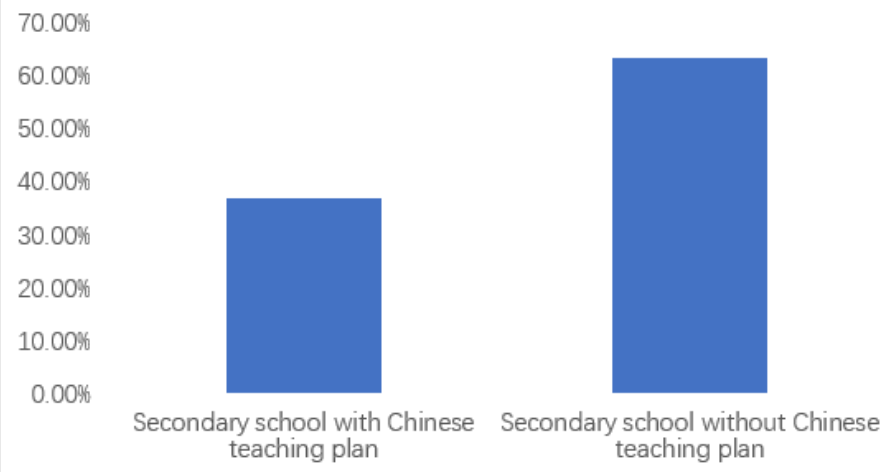

Figure 2. Proportion of Myanmar secondary schools with or without Chinese language teaching plan.

\section{Main Factors Affecting the Effect of Chinese Teaching in Myanmar Middle Schools}

For the main factors affecting the effectiveness of Chinese teaching, the author conducted interviews and questionnaires for 12 Chinese teachers in Myanmar middle schools. The statistical results are shown in Figure 3.
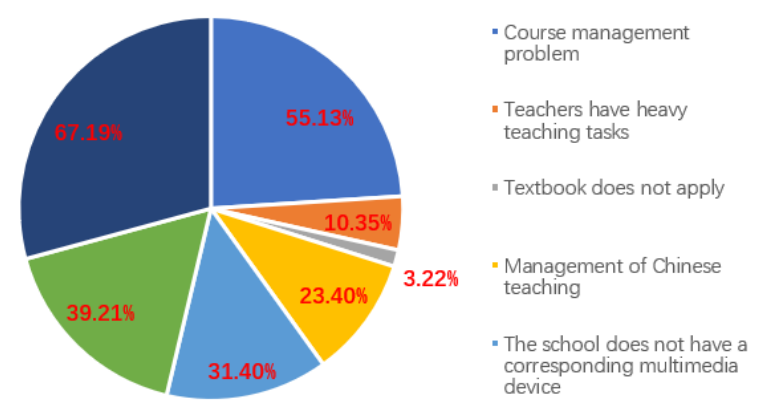

Figure 3. Main factors affecting Chinese teaching in Myanmar middle schools and their proportion.

In summary, due to the fact that the Indonesian Ministry of Education has not yet developed a syllabus for Chinese language courses in primary and secondary schools, the Chinese teaching model developed by various schools is confusing. In terms of teaching management, they are independent, and some schools have formed relatively perfect Chinese teaching management regulations. In some schools, the management of Chinese teaching is almost blank. Even nearly half of the schools do not have Chinese teaching plans, and there are many factors affecting the effectiveness of Chinese teaching. The Chinese teaching in Myanmar middle schools is still in the process of development and exploration, and there are still many places that need to be developed and improved. 


\section{Application of Chinese Teaching Based on the Philosophy of Cognitive Linguistics}

Based on the above analysis of the Chinese language teaching in Myanmar middle schools, combined with the theoretical research of cognitive linguistic philosophy. The analysis of the application of Chinese teaching in middle schools in Myanmar is as follows:

\section{Teaching Design of Cultural Courses}

According to the development direction of philosophy, when people understand the world, they generally follow the order from outside to inside, from things to people. First is empiricism, only theory, or firmly believe that the world is understood through perceptual experience, or firmly believe in "introspection theory", "natural theory", from perceptual knowledge, and pursuing pure reason. This is the extreme of objective philosophy. Only experiential philosophy can dialectically explain the way humans understand the world, and strive to find the cognitive way behind the language. It pays attention to the role of human factors in the process of understanding the world. Therefore, the emergence of experiential philosophy is undoubtedly a great progress in the history of philosophy. It is the philosophical foundation of cognitive linguistics. The order in which language symbols are produced is this: reality-cognition-language. Reality represents the external world. It is cognition, human mental experience and creative thinking. It categorizes and conceptualizes various complicated external worlds, thus constructing a well-ordered meaning system. Then express it in words, either with sound, or with words, or with various nonverbal means. This is not the case with people's growth. The teaching of cultural courses in Chinese education is not only the teaching of cultural knowledge, but also the activity of inheriting ethnic culture. Chinese culture is profound and profound, but our cultural teaching is not to preach abstraction to children and adolescents. The artistic nature of cultural teaching lies in the design of the teaching process as a series of cultural activities that students like to see and do. The teaching process of the cultural curriculum is the process of cultural practice and the process of cultural acquisition. In the teaching design of the cultural curriculum, it is necessary to comprehensively coordinate the related elements such as language teaching and cultural teaching, intramural teaching and social teaching, teaching technology and social environment, activity content and seasonal festivals to make it highly unified. Of course, the acquisition of cultural ability is the "internalization" of the whole, and it is the simultaneous acquisition of spirit and behavior. This classification is mainly the classification of teaching pathways, and the different approaches are a unified teaching process: Depending on the content and the student's situation and the environmental conditions, we can design an optimized teaching process and choose the right way to enter the teaching process. The cultural teaching process of Chinese education. For students, it is a process of close integration of psychological activities and practical operations. It is a highly unified process of "teaching", a process of acquiring the ability of mother tongue culture, and a process of repeated operation, memorization and perception.

\section{Cultural Teaching and Cultural Life under Chinese Teaching}

The philosophy of experience strengthens and perfects the concept of thinking metaphor, and believes that the abstract concept comes from metaphorical thinking. Metaphor is a basic and universal cognitive way for 
human beings to understand the world. It is the basis for people's concept formation, thinking process and cognitive development. The philosophy of experiential philosophy has raised our understanding of language to a new level, bringing us into a new world of language cognition. The principle of experiential philosophy presents a new perspective and explanation for language cognition, which provides new ideas for language research. The three basic principles proposed by the experience philosophy open up new ways of cognitive science research, cognitive linguistics research and philosophical research. This will not only deepen the understanding and understanding of the essence of language, but also gain new discoveries that are conducive to language teaching and acquisition. For the language and culture teaching of Chinese education, it is the integration of teaching activities and practical activities, the unification of teaching and life. In short, the teaching of language and culture in Chinese education is the life of language and culture. Teaching is life and life is teaching. Compared with Chinese language teaching, the cultural teaching of Chinese education has a broader teaching space and is easier to integrate with student life. If Chinese language teaching is the teaching of cultivating students' communicative competence, then cultural teaching is the teaching of cultivating students' cultural communication ability and teaching to guide students' cultural life behavior. The communicative principle of cultural teaching is embodied in making cultural teaching a lively cultural activity and becoming a cultural communication activity in the real life of students. Cultural communication activities in real life, including cultural communication activities between people, and communication activities between people and national culture. In real life, the communicative activities of national culture are more likely to exist among national cultural enthusiasts with common interests. The school's cultural teaching should be combined with the students' cultural life. The first is to establish cultural activities groups and groups at different levels such as schools, classes, and groups. For example, folk songs, folk music, dance, martial arts, calligraphy, Chinese painting, handicrafts, balls and other groups of interested fans; Secondly, these groups and groups are the basic units, and exchanges, performances, competitions, and exhibitions inside and outside the school are held to participate in festivals and folk cultural festivals in the Chinese community and local communities.

\section{Multi-level and multi-modal cooperation in Chinese teaching activities}

The cognitive linguistic experience philosophical view establishes a brand-new philosophical theory, which is the fourth turn after the linguistic turn, the hermeneutic turn, and the rhetorical turn of the philosophy of science. Linguistics has turned to establish the basic position of language in scientific research. It believes that philosophical problems are language problems, and language is the basic and core of philosophical research. Cognitive turn is that the starting point of scientific research should be based on human cognitive structure and process (Burns, Freeman \& Edwards, 2015). Language and knowledge are based on human cognition. Cognitive turn can be said to be a deepening of linguistic turn. The shift of hermeneutics shifts the focus of scientific philosophy to social construction, and the focus is on the social characteristics of science. Cognitive steering attempts to integrate cognitive methods and social historical interpretation methods, and the two develop scientific philosophy from different perspectives. The rhetoric turn emphasizes the role of rhetoric in the development of science, and advocates the use of scientific rhetoric to explain and demonstrate the artistic change or strengthen the concept of understanding value in scientific communication. Middle schools in Myanmar can employ local college graduates in Myanmar and local Chinese talents studying in China. This is 
also the mutual promotion of market and education. In addition, trilingual schools can cooperate with Chinese schools. On the one hand, there can be a relatively stable source of Chinese teachers. As mentioned earlier, most of the trilingual schools have more Chinese teachers than local teachers. At present, Chinese teachers are an important guarantee for the Chinese language teaching level of trilingual schools, and they are attracting students. On the other hand, the cooperative colleges and universities transfer students and students to each other, and mutual benefit and reciprocity. The Chinese language education in the trilingual schools can be continuously assisted by the cooperative Chinese universities, and then they can achieve great development.

\section{Localization changes}

From a philosophical point of view, what Cognitive Linguistics pursues is always the philosophy of experience. In other words, it emphasizes that the real experience of the cognitive subject is an important foothold, and the theoretical concept and research direction are the core, and strive to explore the cognitive way behind the language facts. Under the guidance of this kind of thinking, people's tentacles can be extended to multiple directions, and then they can perceive areas that they have not understood. From the above we have a preliminary understanding of the prototype theory of cognitive language. The application of this theory in Chinese language is mainly reflected in the fact that there is a certain connection between the form and meaning of any language, and this connection does not rely entirely on artificial subjective initiative, but it does have certain rationality. In other words, these connections are based on evidence and have objective reality. Localized textbooks do not translate a Chinese teaching material into a certain language. It is based on the learner's mother tongue culture environment, customs, psychological characteristics and other factors to combine Chinese knowledge and mother tongue culture, reducing the learner's new cognitive content. For young Chinese learners in Myanmar, they have received restrictions on their cognitive level and life experience, and lack of understanding of some things.

For example, the trial version of "Chinese 4" "Xiao Li went to the hospital" appeared in the sentence "Doctor said: 'You have a fever, it is winter, the weather is cold, you have to wear more clothes and drink more water. There is no grammatical and semantic error in this sentence. According to geographical knowledge, Myanmar is a tropical country, and its geography and climate are very different from those of China. It is hot all year round, with no seasons in a year, only two seasons of rain and drought. For young children in tropical countries, most children do not have a winter awareness unless they have experienced winter students. In response to the lack of localization in the trial version of Chinese, a flexible adjustment was made: the adaptor changed the "winter" to the "rainy season" according to the climate characteristics of Indonesia, which is more in line with the students' perceptions.

\section{Case Analysis of Chinese Teaching Based on the Philosophy of Cognitive Linguistics}

\section{Analysis in idiom teaching}

For idioms in Chinese, the meaning of most idioms is by no means a simple addition of each idiom meaning, but to understand idioms from the perspective of holistic and integrated. We believe that from the perspective 
Zhou / Applied Research on Cognitive Linguistic Philosophy in Chinese Teaching.

of cognitive linguistics, idioms should be regarded as a gestalt structure. To discuss the meaning of idioms from a comprehensive perspective, there should be an integrated and harmonious concept, rather than just study from each component, the whole is greater than the sum of the parts. For example, "Open the door to see the mountain" from the various parts to understand, is the "open the door to see the mountain" anti-interest, but if only this understanding is not enough. Mr. Ma Yanhua used the Peking University corpus to search and found that less than $5 \%$ of the examples represent this original meaning, such as:

(1) The Guizhou area is open to the public and seriously hinders the development of the economy. They have to turn their doors to open their doors and see the treasures.

Most of the examples are about its overall meaning. "The metaphor of speaking or writing an article is straightforward to talk about this topic, and it doesn't turn around."

For example: (2) In the first paragraph, the author expresses his point of view at the beginning.

For example, from the perspective of various parts, "riding horses to find horses" is riding a horse to find other horses. However, if we only understand it from this meaning, it will greatly limit the scope of use of this idiom. It is a metaphor that occupies a position and goes to find more satisfactory work. Nowadays, many metaphors are here, and they are still looking around.

For example: a smart person is riding a horse at his eyes, squeezing to a better position, staring at the horse running outside, seeing if there is a better horse to go on.

If we only talk about the meaning of idioms from the meaning of each part, it will misinterpret its meaning. The idioms in Chinese are similar to English, and its literal meaning has been covered by metaphorical meaning. That is, we are talking about the principle of schema transparency, so we must emphasize the metaphorical meaning of idioms, not literal meaning. Ut idioms are analyzable to some extent, and each word basically corresponds to a metaphorical meaning.

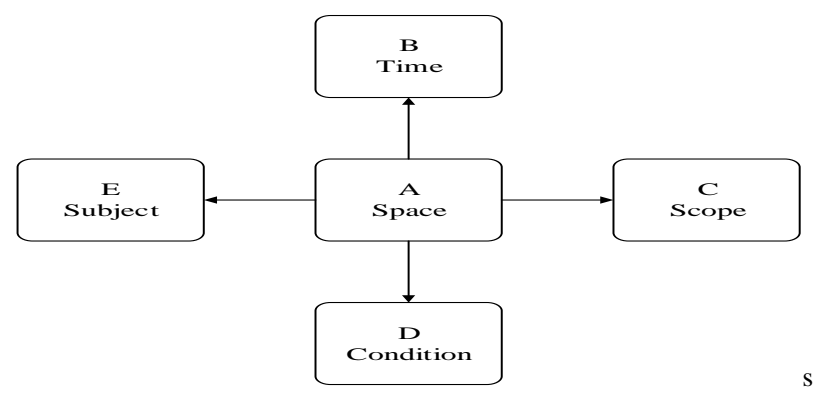

Figure 4. Semantic creation of "in".

\section{Metaphor and polysemy analysis of the preposition "in " in Chinese teaching}

The philosophical view of cognitive linguistics holds that some spatial structures project specific spatial concepts into other abstract conceptual structures through metaphorical methods. In this way, the vocabulary with spatial structure meaning of those steps obtains a specific sensible spatial structure meaning. One such 
cognitive domain is irrelevant and is linked through this metaphor. According to this, we can regard the preposition "in" with a specific meaning space as the archetypal meaning, and the meaning derived from it as non-prototype meaning. In this way we can create a semantic network as shown in Figure 4 around this prototype.

In the figure, A shows the prototype meaning of the preposition "in". And B, C, D, E represent the nonprototype meaning of the preposition "in". The different semantics of "in" are mainly represented by "up-down" and container diagrams. Such as: Meet and change on Sunday. Time (Sunday) is cognitively a time domain, which we metaphorically understand as a container of a truly sensible concrete three-dimensional structure. There are a variety of things that can happen in this container. These things are the body of the cognitive linguistic philosophy. "Yes" is the link between time and space. It metaphorizes the specific spatial domain metaphor to the abstract time domain, so that "in" the introduction time is understandable.

\section{Conclusion}

The development of language is a manifestation of the continuous progress of human civilization. The philosophical view of cognitive linguistics is indispensable in Chinese teaching. The viewpoints and theories in the philosophical view of cognitive linguistics have an indispensable meaning for Chinese teaching, with the help of it. Learners with different native languages can use the relevant theories and rules to explain Chinese grammar with the help of cognitive linguistics. It seems that Chinese teachers should master certain knowledge of cognitive linguistic theories and apply them to teaching Chinese as a foreign language through teaching practice. This will not only improve the quality of teaching, but also promote students' better learning, and stimulate the interest and enthusiasm of foreign students to learn Chinese, so that Chinese learning in China will be carried forward in the world.

\section{References}

Burns, A., Freeman, D., \& Edwards, E. (2015). Theorizing and studying the language-teaching mind: Mapping research on language teacher cognition. The Modern Language Journal, 99(3), 585-601. https://dx.doi.org/10.1111/modl.12245

Chen, J. (2015). Teachers' conceptions of approaches to teaching: A Chinese perspective. The Asia-Pacific Education Researcher, 24(2), 341-351. http://dx.doi.org/10.1007/s40299-014-0184-3

Duan, C., Hill, C. E., Jiang, G., Hu, B., Lei, Y., Chen, J., Yu, L. (2015). The counselor perspective on the use of directives in counseling in China: Are directives different in China as in the United States. Counselling Psychology Quarterly, 28(1), 57-77. http://dx.doi.org/10.1080/09515070.2014.965659

Hulstijn, J. H., Young, R. F., Ortega, L., Bigelow, M., DeKeyser, R., Ellis, N. C., \& Talmy, S. (2014). Bridging the gap: Cognitive and social approaches to research in second language learning and teaching. Studies in Second Language Acquisition, 36(3), 361-421. https://dx.doi.org/10.1017/S0272263114000035 
Zhou / Applied Research on Cognitive Linguistic Philosophy in Chinese Teaching.

Kubanyiova, M., \& Feryok, A. (2015). Language teacher cognition in applied linguistics research: Revisiting the territory, redrawing the boundaries, reclaiming the relevance. The Modern Language Journal, 99(3), 435-449. http://dx.doi.org/10.1111/modl.12239

Koh, K., Burke, L., Luke, A., Gong, W., Tan, C. (2018). Developing the assessment literacy of teachers in Chinese language classrooms: A focus on assessment task design. Language Teaching Research, 22(3), 26488. http://dx.doi.org/10.1177/1362168816684366

Kubanyiova, M. (2015). The role of teachers' future self-guides in creating L2 development opportunities in teacher-led classroom discourse: Reclaiming the relevance of language teacher cognition. The Modern Language Journal, 99(3), 565-584. https://dx.doi.org/10.1111/modl.12244

Orton, J. (2016). Issues in Chinese language teaching in Australian schools. Chinese Education \& Society, 49(6): 369-375. https://dx.doi.org/10.1080/10611932.2016.1283929

Sakita, T. I. (2006). Parallelism in conversation: Resonance, schematization, and extension from the perspective of dialogic syntax and cognitive linguistics. Pragmatics \& Cognition, 14(3), 467-500. https://dx.doi.org/10.1075/pc.14.3.03sak

Tsai, C. H., Wang, C. P. (2015). Taiwan's Chinese language development and the creation of language teaching analysis. Universal Journal of Educational Research, 3(3), 220-228. https://dx.doi.org/10.13189/ujer.2015.030308

Wu, P. (2018). College Chinese teaching and improvement of college students' humanistic quality. Creative Education, 9(07), 1061. https://dx.doi.org/10.4236/ce.2018.97079

Zima, E. (2013). Cognitive grammar and dialogic syntax: Exploring potential synergies. Annual Review of Cognitive Linguistics, 11(1), 36-72. http://dx.doi.org/10.1075/rcl.11.1.02zim 